\section{UF $\mid$ FLORIDER}

IFAS Extension
IFAS Analytical Services Laboratories Extension Soil Testing Laboratory

PO Box 110740 / Wallace Building 631, UF / Gainesville, FL 32611-0740 EMAIL: SOILSLAB@IFAS.UFL.EDU WEBSITE: SOILSLAB.IFAS.UFL.EDU

\title{
Pine Nursery Soil Test Information Sheet
}

Mailing Address (please print)

Note: This Lab Only Tests Samples from the State of Florida.

Name

Phone

Address

City

FL Zip

Date

E-Mail *

Direct any questions

regarding this test or the interpretation of the results to your county Extension Agent.

* In order to expedite reporting of results; please provide an e-mail address if possible.

A pine nursery soil test includes soil $\mathrm{pH}$, organic matter, and Mehlich-I extractable $\mathrm{P}, \mathrm{K}, \mathrm{Mg}$ and $\mathrm{Ca}$.

Fill in all requested information, using one line per sample and additional sheets for more than 10 samples.

\begin{tabular}{|l|l|l|c|}
\hline Lab Use Only & Sample Identification & County & Cost \\
\hline & & & $\$ 10.00$ \\
\hline & & & $\$ 10.00$ \\
\hline & & & $\$ 10.00$ \\
\hline & & & $\$ 10.00$ \\
\hline & & & $\$ 10.00$ \\
\hline & & & $\$ 10.00$ \\
\hline
\end{tabular}

Check

Money Order

Cash

Total

SAMPLES WILL NOT BE PROCESSED WITHOUT PAYMENT.

Please enclose payment and this sheet in the same package as sample(s).

Do not send cash through the mail.

\section{Important Information For Sample Collection and Submission}

Sampling of pine nursery soil is an effective tool to assist in fertilizer management decisions.

1. Each soil sample should be a mixed composite of $\mathbf{1 5}$ to 20 soil cores taken randomly from throughout each management unit. Only one depth, 0 to 6 inches, need be sampled. The objective is to obtain a sample which represents the entire management unit. Do not include cores from nonrepresentative or problem spots. Sample such areas separately, if needed.

2. Label each sample bag and record the same label in the "sample identification" column above.

3. Spread composite sample on paper or other suitable material to air dry. Mix the dried sample thoroughly and put about 1 pint of soil in a labeled sample bag.
4. Calculate the cost at $\$ 10.00$ per sample. Please make your check or money order payable to University of Florida.

5. Include this sheet and payment in the shipping box with your samples. Soil sample bags and addressed shipping boxes are available at no charge from your county Cooperative Extension Service office.

6. Test results

A soil test report will be emailed / mailed to you within 5 to 10 days after your sample arrives at the Extension Soil Testing Laboratory. Contact your county Extension office if you have questions concerning the Soil Test Report. 